\title{
HOXB13 expression and promoter methylation as a candidate biomarker in gastric cancer
}

\author{
BAI-QIANG SUI, CHUN-DONG ZHANG, JI-CHAO LIU, LEI WANG and DONG-QIU DAI \\ Department of Gastrointestinal Surgery, The Fourth Affiliated Hospital of China Medical University, \\ Shenyang, Liaoning 110032, P.R. China
}

Received April 16, 2016; Accepted July 3, 2017

DOI: $10.3892 / 01.2018 .8371$

\begin{abstract}
Homeobox b13 (HOXB13) is considered to be a tumor suppressor gene in multiple types of human cancer. The present study aimed to identify the difference in expression of HOXB13 mRNA between gastric cancer (GC) tissues and corresponding non-malignant gastric tissues. The clinical significance of HOXB13 mRNA expression was also assessed in $\mathrm{GC}$ and a potential association between HOXB13 mRNA expression and DNA promoter methylation was observed. The expression of HOXB13 mRNA was assessed by reverse transcription-quantitative polymerase chain reaction (RT-qPCR) and HOXB13 methylation status was assessed by methylation-specific PCR (MSP) in 5 GC cell lines and 85 paired GC and normal gastric tissues. Kaplan-Meier survival curves were used to assess the survival of patients with GC. HOXB13 mRNA expression was significantly lower in primary $\mathrm{GC}$ tissues than in corresponding nonmalignant gastric tissues, and decreased HOXB13 expression was associated with poorer differentiation, lymph node metastasis, invasion depth and Tumor-Node-Metastasis (TNM) stage. Kaplan-Meier survival analysis demonstrated that HOXB13 mRNA expression was a significant prognostic indicator of GC patient survival. Furthermore, MSP revealed that the proportion of GC samples with hypermethylated HOXB13 $(60.0 \%, 51 / 85)$ was increased compared with the corresponding nonmalignant gastric tissues $(11.8 \%, 10 / 85)$. Decreased HOXB13 mRNA expression was due to DNA hypermethylation as following treatment with the DNA methyltransferase inhibitor 5-Aza-dC, HOXB13 expression in the GC MKN-45 cell line was upregulated. The results of the present study indicate that decreased expression of HOXB13 mRNA was associated with tumor differentiation, depth of invasion, lymph node metastases and TNM stage in
\end{abstract}

Correspondence to: Professor Dong-Qiu Dai, Department of Gastrointestinal Surgery, The Fourth Affiliated Hospital of China Medical University, 4 Chongshan East Road, Shenyang, Liaoning 110032, P.R. China

E-mail: daidq63@126.com; daidq63@163.com

Key words: homeobox b13, gastric cancer, gene expression, DNA methylation, prognosis
$\mathrm{GC}$, and it was a significant poor prognostic factor for patients with GC. Aberrant DNA promoter methylation was a crucial reason for the downregulation of HOXB13 mRNA expression.

\section{Introduction}

Gastric cancer (GC) is the fourth most common malignant disease globally and is the second highest mortality rate due to cancer globally (1). Owing to the poor response to treatment observed in patients with advanced-stage GC, the 5-year overall survival (OS) rate is in the range of $25-30 \%$ worldwide (2). Therefore, it is necessary to diagnose GC at an early stage. Understanding the molecular mechanisms underlying GC development is also essential for determining methods to inhibit tumor progression.

The homeobox B13 (HOXB13) gene belongs to the HOX family, which are known to function in encoding nuclear transcription factors involved in establishing and maintaining patterns of differentiation during development (3). The HOXB13 gene, which is located in chromosomal region 17q21.2, encodes a 31-kDa protein (4). The 5'end of HOXB13 contains two $\mathrm{CpG}$ islands, one in the promoter/exon1 and the other $4.5 \mathrm{~kb}$ upstream of the transcription start site, suggesting that HOXB13 gene expression may be controlled by DNA methylation (5). Mice with loss-of-function mutations in HOXB13 exhibited an overgrown-tail phenotype, with increased cell proliferation and decreased apoptosis in the tail; this evidence indicated that HOXB13 inhibited proliferation and activated programmed cell death (6). Overexpression of HOXB13 inhibited prostate cell proliferation, inducing G1-phase cell cycle arrest as mediated by downregulation of T-cell factor-4 (TCF-4) expression (7). HOXB13 also downregulated the expression of TCF-4 at the protein level, suppressing the growth of colorectal cancer cells (8). HOXB13 also serves diverse biological functions in embryonic development and terminally differentiated tissue $(9,10)$.

Many studies have identified HOXB13 as a candidate tumor suppressor gene in several types of cancer, including colorectal cancer (8), renal cancer (11), melanoma (12) and breast cancer (13). Additionally, hypermethylation of the HOXB13 gene promoter was a potential mechanism for decrease expression $(8,13-15)$. Other studies, however, revealed that HOXB13 was overexpressed in numerous types of tumor, potentially contributing to carcinogenesis and 
tumor progression in prostate $(16)$, breast $(17)$, ovarian $(18,19)$, cervical (20) and oral cancer (21). The HOXB13 germline variant G84E mutation may be involved in promoting tumor progression, with the function of HOXB13 depending on the tissue in which expressed $(22,23)$. Although previous studies have demonstrated that HOXB13 is a contrasting biomarker for tumor development in numerous types of cancer, the function of HOXB13 in gastric cancer is unclear $(8,11-21)$.

To understand the function of the HOXB13 gene in GC, the present study detected the expression levels of HOXB13 mRNA in gastric cancer tissues and corresponding non-malignant gastric tissues and then evaluated the association between HOXB13 mRNA expression and survival time. The methylation status of HOXB13 in GC cell lines and GC tissues was also detected, and then the association between its expression and DNA methylation was assessed.

\section{Materials and methods}

Patients and tissue samples. The present study included 85 patients in total, which included 45 males and 40 females. The average age was 61 years old and the age range was 35-75. All patients underwent gastrectomy between September 2007 and August 2012 at the Fourth Affiliated Hospital of China Medical University (Shenyang, China). Gastric tissue specimens and corresponding nonmalignant gastric tissues were collected following tumor excision during gastrectomy and were diagnosed by at least two pathologists. Tumor classification was performed according to the Tumor-Node-Metastasis (TNM) grading system, seventh edition (24). Following this, patients were monitored periodically and their tumor marker levels, including carcinoembryonic antigen and carbohydrate antigen 19-9 assessed, their blood tested, chest and abdominal computed tomography images captured and gastroscopy performed. OS rates were defined as the time from surgery to mortality or the last follow-up. The final follow-up date was February 2016. The median duration of follow-up was 26 months (range 5-90 months). The present study was approved by the Research Ethics Committee of China Medical University (Shenyang, China). All patients provided written informed consent to participate in this research.

Reverse transcription-quantitative polymerase chain reaction $(R T-q P C R)$. Total RNA was extracted using TRIzol reagent (Invitrogen; Thermo Fisher Scientific, Inc., Waltham, MA, USA) from tissues or cultured cells. cDNA was synthesized from RNA by using an Expanding Reverse Transcriptase kit (Takara Bio, Inc., Otsu, Japan) according to the manufacturer's protocol. qPCR was used to detect the expression of HOXB13 mRNA in a reaction volume of $25 \mu \mathrm{l}$, including $12.5 \mu \mathrm{l} \mathrm{SYBR}$ Green (Takara Bio, Inc.), $2 \mu \mathrm{l}$ cDNA, $1 \mu \mathrm{l}$ of each primer and $8.5 \mu \mathrm{l}$ diethyl pyrocarbonate water. The mixture was incubated by the following program: $95^{\circ} \mathrm{C}$ for $30 \mathrm{sec}, 40$ cycles of $95^{\circ} \mathrm{C}$ for $5 \mathrm{sec}, 60^{\circ} \mathrm{C}$ for $32 \mathrm{sec}$. The primers used were: HOXB13 forward, 5'-TGTTGCCAGGGAGAACAGAAC-3' and reverse, 5'-CGCTGGAGTCTGCAAATGCT-3' (25); and $\beta$-actin (ACTB) forward, 5'-TGGCACCCAGCACAATGA A-3' and reverse, 5'-CTAAGTCATAGTCCGCCTAGAAGC A-3'. For each PCR, diethyl pyrocarbonate water was used as a negative control. The expression level of HOXB13 mRNA was standardized to the ACTB mRNA expression level, and data was quantified using the $2^{-\Delta \Delta C q}$ method (26).

Gastric cells and culture. The SGC-7901, BGC-823, MGC-803, MKN-45 and AGS GC cell lines, and the immortalized normal gastric GES-1 cell line (as the control), were obtained from the Institute of Biochemistry and Cell Biology, Chinese Academy of Sciences (Shanghai, China). Cells were cultured in RPMI 1640 (Invitrogen; Thermo Fisher Scientific, Inc.). Cell lines were cultured with $10 \%$ fetal bovine serum (Thermo Fisher Scientific, Inc.) at $37^{\circ} \mathrm{C}$ in a humidified incubator with $5 \% \mathrm{CO}_{2}$.

Western blot analysis. Total protein in cultured cells and tissue specimens was extracted using the Qproteome Mammalian Protein Prep kit (Qiagen GmbH, Hilden, German) and protein concentration was determined with a BCA Protein Assay kit (Bio-Rad, Milan, Italy). Protein samples were denatured by boiling for $5 \mathrm{~min}$ and $30 \mu \mathrm{g}$ protein samples were electrophoresed by $12 \%$ SDS-PAGE. The protein samples were then transferred to polyvinylidene fluoride membranes. Following blocking with blocking buffer $(5 \%$ skim milk in $50 \mathrm{mM}$ Tris- $\mathrm{HCl}, 200 \mathrm{mM} \mathrm{NaCl}$ and $0.05 \%$ Tween-20, pH 7.5) for $2 \mathrm{~h}$ at room temperature, membranes were incubated overnight at $4^{\circ} \mathrm{C}$ with the HOXB13 antibody (1:1,000; cat. no. ab28575) or ACTB antibody (cat. no. ab6276; both Abcam, Cambridge, MA, USA). The next day, those membranes were washed three times with PBS and incubated for $120 \mathrm{~min}$ at room temperature with a horseradish peroxidase conjugated goat anti-rabbit immunoglobulin G secondary antibody (cat. no. A0545; 1:1,000; Sigma-Aldrich; Merck KGaA, Darmstadt, Germany). Following washing, the immunoreactive protein bands were visualized using an Electrochemiluminescence Detection kit (cat. no. P0018; Beyotime Institute of Biotechnology, Haimen, China). Each experiment was repeated at least three times.

DNA extraction and methylation-specific PCR (MSP). Total DNA was extracted from MKN-45 and tissue specimens using the Takara Universal Genomic DNA Extraction kit Ver.3.0 (Takara Bio, Inc.), according to the manufacturer's protocol. The EZ DNA Methylation-Gold kit (Zymo Research, Irvine, CA, USA) was used to perform bisulfite conversion for subsequent methylation analysis. The primers used for MSP were complementary to the promoter region of the HOXB13 gene. The primers were as follows: Methylated HOXB13 CpG islands forward, 5'-TATTTTGGATGGAGTTAAGGA TATC-3' and reverse, 5'-ATAATTAACAACAAACATCAA CGTA-3'; and unmethylated HOXB13 CpG islands forward, 5'-ATTTTGGATGGAGTTAAGGATATTG-3' and reverse, 5'-CATAATTAACAACAAACATCAACATA-3' (27). The reaction mixture was in a volume of $50 \mu \mathrm{l}$ containing $1 \mu \mathrm{l}$ DNA, 2X GC buffer I, $1 \mu$ l of each primer, $2.5 \mathrm{mM}$ dNTP Mix and $2.5 \mathrm{U}$ LA Taq polymerase (Takara Bio, Inc.). The MSP conditions were as follows: $94^{\circ} \mathrm{C}$ for $5 \mathrm{~min}, 40$ cycles of $94^{\circ} \mathrm{C}$ for $30 \mathrm{sec}, 54^{\circ} \mathrm{C}$ for $30 \mathrm{sec}, 72^{\circ} \mathrm{C}$ for $45 \mathrm{sec}$ and $72^{\circ} \mathrm{C}$ for $10 \mathrm{~min}$. The GES-1 cell line and peripheral blood cell-derived DNAs treated with the CpG methlytransferase SssI (New England Biolabs, Ipswich, MA, USA) were used as negative and positive controls respectively. All procedures were repeated at least three times. The PCR products were subjected to $2 \%$ agarose 

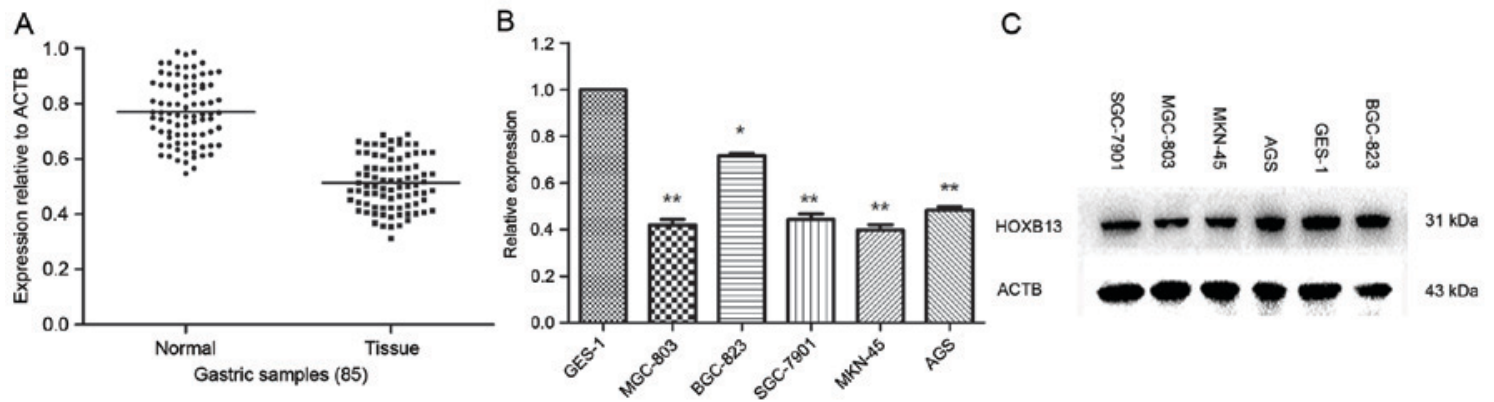

Figure 1. HOXB13 expression in GC tissues and GC cell lines. (A) HOXB13 mRNA expression in 85 gastric specimens and corresponding nonmalignant gastric tissues. (B) HOXB13 mRNA expression in HOXB13 mRNA expression in five GC cell lines and GES-1. (C) HOXB13 protein expression in five GC cell lines and GES-1. ${ }^{*} \mathrm{P}<0.05,{ }^{* *} \mathrm{P}<0.01$ vs. GES-1. GC, gastric cancer; HOXB13, homeobox B13; ACTB, $\beta$-actin.

gel electrophoresis at $120 \mathrm{~V}$ for $40 \mathrm{~min}$ and quantified using the Fluor Chen 2.0 system.

5-Aza-cytidine treatment. MKN-45 cells were plated at a density of $5 \times 10^{5}$ cells per well into 6 -well cell culture plates and incubated at $37^{\circ} \mathrm{C}$ in a humidified incubator with $5 \% \mathrm{CO}_{2}$. Following culturing overnight, 0,5 or $10 \mu \mathrm{mol} / 1$ 5-Aza-dC (Sigma-Aldrich; Merck KGaA) was added and cells were incubated for 3 days, with $1.0 \mu \mathrm{mol} / 1$ trichostatin A (TSA; Beyotime Institute of Biotechnology) added on the final day at room temperature. Next, total RNA and DNA was extracted for detecting HOXB13 mRNA and protein expression levels as aforementioned.

Statistical analysis. All statistical analysis was performed using SPSS 19.0 software (IBM Corp., Armonk, NY, USA). Paired Student's t-test was used to analyze the association between HOXB13 mRNA expression and clinicopathological features. Kaplan-Meier curves and log-rank tests were used to estimate the influence of HOXB13 mRNA expression on OS. Cox's proportional hazard model was used to assess hazard ratios and corresponding 95\% confidence intervals. One-way analysis of variance (ANOVA) was used to assess the associations between HOXB13 expression and methylation status. $\mathrm{P}<0.05$ was considered to indicate a statistically significant difference.

\section{Results}

Downregulation of HOXB13 mRNA expression in gastric cell lines and tissues. HOXB13 mRNA expression levels were analyzed in $85 \mathrm{GC}$ tissues and corresponding non-malignant tissues. RT-qPCR revealed that the expression of HOXB13 mRNA in GC tissues was distinctly lower than those in corresponding non-malignant tissues (Fig. 1A). The expression of HOXB13 mRNA and protein levels were further examined by RT-qPCR and western blotting in six gastric cell lines (five cancer, one non-cancer). The results which used Student's t-test revealed that HOXB13 mRNA and protein expression levels were significantly lower in three of the five GC cells lines compared with GES-1 (the non-cancer control; Fig. 1B and C). It was worth noting that HOXB13 protein expression levels were lower in MGC-803 and MKN-45 cells compared with GES-1 cells in Fig. 1C. As there may exist translation level adjustment, protein expression levels are not necessarily in accordance with mRNA expression levels.

Association between expression of HOXB13 mRNA and clinicopathological features. The associations between HOXB13 mRNA expression and the clinicopathological factors of 85 patients with GC were assessed. As presented in Table I, HOXB13 mRNA expression was significantly associated with tumor differentiation $(\mathrm{P}=0.008)$, tumor invasion depth $(\mathrm{P}=0.027)$, the presence of lymph node metastases $(\mathrm{P}=0.016)$ and TNM stage $(\mathrm{P}=0.007)$. However, HOXB13 mRNA expression was not associated with the clinicopathological features tested, including age, sex, tumor location, tumor size and Borrmann type (Table I) (28).

Expression of $H O X B 13$ mRNA relative to prognosis. Kaplan-Meier survival curves were constructed to assess the prognostic significance of HOXB13 mRNA expression and various clinicopathological features (Table II). mRNA expression levels in GC tissues were distinguished by comparing with the mean expression quantity (0.771) of HOXB13 mRNA in 85 non-malignant gastric tissues. A total of 22 patients expressed higher quantities and 63 patients expressed lower quantities of HOXB13. HOXB13 mRNA expression was inversely associated with 5-year OS. In patients expressing low amounts of HOXB13 mRNA, OS rate was $42.9 \%$, which was lower compared with the 5-year OS rate of $68.2 \%$ (Log-rank test, $\mathrm{P}<0.05$ ) in patients expressing high levels of HOXB13. Similarly, tumor differentiation, invasion depth, Borrmann type and TNM stage were revealed to be associated with OS rates. Cox multivariate analysis was performed on expression of HOXB13 mRNA, invasion depth, differentiation, Borrmann type and TNM stage. This analysis revealed that HOXB13 mRNA expression, invasion depth, differentiation and Borrmann type all acted as independent prognostic factors for OS (Table III and Fig. 2).

Promoter methylation status of HOXB13 gene in gastric cell lines and tissues. The methylation status of HOXB13 gene promoter $\mathrm{CpG}$ islands was assessed by MSP. The data revealed that the HOXB13 gene promoter was hypermethylated in BGC823, AGS, MKN45 and SGC-7901 cells, partially methylated in MGC-803 cells, and unmethylated in GES1 cells (Fig. 3A). Hypermethylation of the HOXB13 gene promoter was observed in $60 \%(51 / 85)$ of gastric cancer tissue 
Table I. Associations between the clinicopathological features and HOXB13 mRNA expression.

\begin{tabular}{|c|c|c|c|}
\hline Variable & Patients (n) & HOXB13 mRNA level ${ }^{\mathrm{a}}$ & P-value \\
\hline Non-malignant tissues & 85 & $0.771 \pm 0.114$ & $<0.001^{\mathrm{b}}$ \\
\hline Tumor tissues & 85 & $0.514 \pm 0.095$ & \\
\hline Age, years & & & 0.200 \\
\hline$\geq 65$ & 42 & $0.535 \pm 0.088$ & \\
\hline$<65$ & 43 & $0.508 \pm 0.102$ & \\
\hline Sex & & & 0.165 \\
\hline Male & 45 & $0.508 \pm 0.095$ & \\
\hline Female & 40 & $0.537 \pm 0.095$ & \\
\hline Location & & & 0.738 \\
\hline Upper/middle & 38 & $0.517 \pm 0.100$ & \\
\hline Lower & 47 & $0.524 \pm 0.092$ & \\
\hline Size, $\mathrm{cm}$ & & & 0.216 \\
\hline$<5$ & 41 & $0.508 \pm 0.930$ & \\
\hline$\geq 5$ & 44 & $0.534 \pm 0.098$ & \\
\hline Borrmann type & & & 0.077 \\
\hline $\mathrm{I}+\mathrm{II}$ & 30 & $0.546 \pm 0.095$ & \\
\hline III+IV & 55 & $0.508 \pm 0.094$ & \\
\hline Differentiation & & & $0.008^{\mathrm{b}}$ \\
\hline Well/moderate & 39 & $0.551 \pm 0.087$ & \\
\hline Poor & 46 & $0.496 \pm 0.097$ & \\
\hline Invasion depth & & & $0.027^{\mathrm{b}}$ \\
\hline $\mathrm{T} 1+\mathrm{T} 2$ & 36 & $0.548 \pm 0.091$ & \\
\hline $\mathrm{T} 3+\mathrm{T} 4$ & 49 & $0.502 \pm 0.095$ & \\
\hline TNM stage & & & $0.007^{\mathrm{b}}$ \\
\hline $\mathrm{I}+\mathrm{II}$ & 34 & $0.556 \pm 0.095$ & \\
\hline III+IV & 51 & $0.499 \pm 0.090$ & \\
\hline Lymph node metastasis & & & $0.016^{\mathrm{b}}$ \\
\hline No & 32 & $0.554 \pm 0.083$ & \\
\hline Yes & 53 & $0.502 \pm 0.099$ & \\
\hline
\end{tabular}

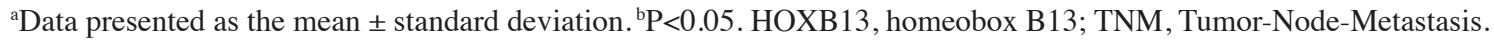

specimens (Fig. 3B), but in only $11.8 \%$ (10/85) of corresponding non-malignant gastric tissues. The 10 hypermethylated adjacent non-malignant gastric tissues had postoperative pathological diagnoses of intestinal metaplasia or hyperplasia.

5-Aza-dC treatment induces upregulated expression of HOXB13. To assess whether methylation of the HOXB13 gene promoter was responsible for downregulation of HOXB13 expression, the cell line with the lowest expression (MKN-45) was treated with the DNA methylation inhibitor 5-Aza-dC and the histone deacetylase inhibitor TSA. The results which were assessed by one-way ANOVA demonstrated that 5-Aza-dC upregulated HOXB13 expression, with the highest expression occurring at a concentration of $15 \mu \mathrm{M}$ 5-Aza-dC. HOXB13 expression was also restored with a combination treatment of 5-Aza-dC and TSA, but this was only slightly higher than that induced by 5-Aza-dC alone ( $\mathrm{P}<0.05$; Fig. 4A). HOXB13 protein expression was also increased in MKN-45 cells following 5-Aza-dC treatment (Fig. 4B).
Association between expression of HOXB13 mRNA and methylation status. One-way ANOVA was used to assess the association between HOXB13 mRNA expression and DNA methylation status in 85 GC tissues: mRNA expression of HOXB13 was significantly lower in tissues with methylated promoter regions than in tissues with partial or no methylation. However, there was no difference in expression of HOXB13 between tissues with partial HOXB13 promoter methylation and no HOXB13 promoter methylation. Therefore, low HOXB13 expression was associated with DNA hypermethylation.

\section{Discussion}

DNA methylation is a heritable epigenetic alteration that does not alter the DNA nucleotide sequence but is involved in transcriptional repression (29). Methylation of DNA at promoter $\mathrm{CpG}$ islands where transcription is initiated leads to the silencing of tumor suppressor genes, which contributes directly to cancer development $(30,31)$. Previous studies have 
Table II. Univariate analysis of survival in gastric cancer cases, assessed using the log rank test.

\begin{tabular}{|c|c|c|}
\hline Variable & 5-year OS & P-value \\
\hline Age, years & & 0.499 \\
\hline$\geq 65$ & 41.9 & \\
\hline$<65$ & 38.1 & \\
\hline Sex & & 0.409 \\
\hline Male & 40.0 & \\
\hline Female & 40.0 & \\
\hline Location & & 0.701 \\
\hline Upper/middle & 44.7 & \\
\hline Lower & 42.5 & \\
\hline Size, cm & & 0.763 \\
\hline$<5$ & 38.6 & \\
\hline$\geq 5$ & 41.5 & \\
\hline Borrmann type & & $<0.001^{\mathrm{a}}$ \\
\hline $\mathrm{I}+\mathrm{II}$ & 73.3 & \\
\hline III+IV & 21.8 & \\
\hline Differentiation & & $<0.001^{\mathrm{a}}$ \\
\hline Well/moderate & 66.7 & \\
\hline Poor & 17.4 & \\
\hline Invasion depth & & $<0.001^{\mathrm{a}}$ \\
\hline $\mathrm{T} 1+\mathrm{T} 2$ & 66.7 & \\
\hline $\mathrm{T} 3+\mathrm{T} 4$ & 20.4 & \\
\hline Lymph node metastasis & & 0.072 \\
\hline No & 53.1 & \\
\hline Yes & 32.1 & \\
\hline TNM stage & & $0.021^{\mathrm{a}}$ \\
\hline $\mathrm{I}+\mathrm{II}$ & 50.0 & \\
\hline III+IV & 33.3 & \\
\hline HOXB 13 mRNA expression & & $0.010^{\mathrm{a}}$ \\
\hline High & 68.2 & \\
\hline Low & 42.9 & \\
\hline
\end{tabular}

${ }^{\mathrm{a}} \mathrm{P}<0.05$. HOXB13, homeobox B13; TNM, Tumor-Node-Metastasis.

revealed that numerous tumor suppressor genes undergo aberrant DNA methylation in GC $(32,33)$.

HOXB13 gene expression was observed during the late development of the tailbud and posterior of mouse embryos and HOXB13 expressed in the spinal, digestive and urogenital system in humans (34). A number of studies have revealed a decrease in HOXB13 expression in colorectal cancer (5), renal cancer (11), melanoma cancer (12) and breast cancer (13), making it a candidate tumor suppressor gene. Promoter hypermethylation of the HOXB13 gene is considered to be a potential mechanism for decreased expression $(13-15,34)$.

In the present study, HOXB13 mRNA expression was revealed to be decreased in five GC cell lines, compared with the normal gastric cell line GES-1; HOXB13 mRNA expression was also significantly lower in GC tissues than in non-malignant gastric tissues. These data demonstrated that HOXB13 may act as a candidate tumor suppressor in GC. In the 22 GC cases where HOXB13 mRNA expression was higher than the mean expression quantity in adjacent nonmalignant gastric tissues, the HOXB13 promoter was unmethylated in 12 cases and partially methylated in 10 cases (none were hypermethylated). This result indicated that the expression of HOXB13 mRNA in GC was markedly affected by DNA methylation. HOXB13 mRNA expression was associated with tumor differentiation, invasion depth, lymph node metastasis and TNM stage. Notably, the expression of HOXB13 mRNA in poorly differentiated GC tissues was lower than that in well/moderately differentiated GC tissues. Poorly differentiated GC cells possess higher malignancy than well/moderate differentiated cells, indicating that the decrease in HOXB13 mRNA expression occurs in more malignant cases of GC. HOXB13 mRNA expression is lower in GC tissues than adjacent non-malignant gastric tissues, which, along with later TNM stage and deeper invasion depth, means greater disease progression of GC. The expression of HOXB13 mRNA in GC with lymph node metastasis is significantly lower than GC without lymph node metastasis. Marra et al (35) reported that the loss of HOXB13 expression in non-muscle-invasive bladder transitional cancer is significantly associated with shorter disease-free survival. The results of a log-rank test revealed that there were significant differences in OS between patients of HOXB13 mRNA low expression and patients of HOXB13 mRNA high expression. The results of Cox proportional hazards model analysis demonstrated that expression of HOXB13 mRNA was an independent prognostic marker for OS. Decreased HOXB13 mRNA expression may therefore act as a potential predictor of the degree of GC malignancy and overall disease prognosis, results that are also supported by Okuda et al (14).

A previous study revealed that epigenetic mechanisms, including DNA methylation, were associated with tumor development and progression (36). Promoter hypermethylation was the mechanism underlying the decreased expression of HOXB13. In the present study, the HOXB13 gene was hypermethylated in all but one GC cell lines, and partially methylated in MGC-803. Aberrant methylation of the HOXB13 promoter was also observed in GC tissue samples. Hypermethylation of the HOXB13 gene promoter was identified in $51(60.0 \%)$ of the 85 gastric tissues, while methylation in was only detected in 10 non-malignant adjacent gastric tissues (11.8\%). Additionally, adjacent nonmalignant gastric tissues in hypermethylation status may be associated with tissue accompanied with precancerous lesions. To examine the association between the methylation status of the HOXB13 promoter and HOXB13 expression, a one-way ANOVA was used. The results of this analysis demonstrated that expression of HOXB13 in GC tissues with a hypermethylated HOXB13 promoter was markedly lower compared with the expression of HOXB13 in GC tissues with partially methylated or unmethylated HOXB13 promoters. However, there was no marked difference between the expression of HOXB13 in GC tissues with partially methylated promoter and the expression of HOXB13 in GC tissues with unmethylated promoters. These data revealed that low HOXB13 expression was caused by DNA hypermethylation and indicated that the methylation of HOXB13 may enhance the degree of malignancy of GC. 
Table III. Multivariate analysis of survival in gastric cancer cases, assessed using the log rang test.

\begin{tabular}{lcccr}
\hline Variable & B & SE & P-value & HR (95\% CI) \\
\hline Borrmann type & 1.068 & 0.267 & $<0.001^{\mathrm{a}}$ & $2.901(1.723-4.914)$ \\
Differentiation & 0.918 & 0.259 & $<0.001^{\mathrm{a}}$ & $2.504(1.506-4.163)$ \\
Invasion depth & 0.930 & 0.274 & $0.001^{\mathrm{a}}$ & $2.535(1.480-4.341)$ \\
TNM stage & 0.062 & 0.147 & 0.675 & $1.063(0.798-1.418)$ \\
HOXB13 mRNA expression & -0.699 & 0.312 & $0.025^{\mathrm{a}}$ & $0.497(0.270-0.915)$
\end{tabular}

${ }^{\mathrm{a}} \mathrm{P}<0.05$. HOXB13, homeobox B13; B, regression coefficient; SE, standard error; HR, hazard ratio; CI, confidence interval; TNM, Tumor-Node-Metastasis.

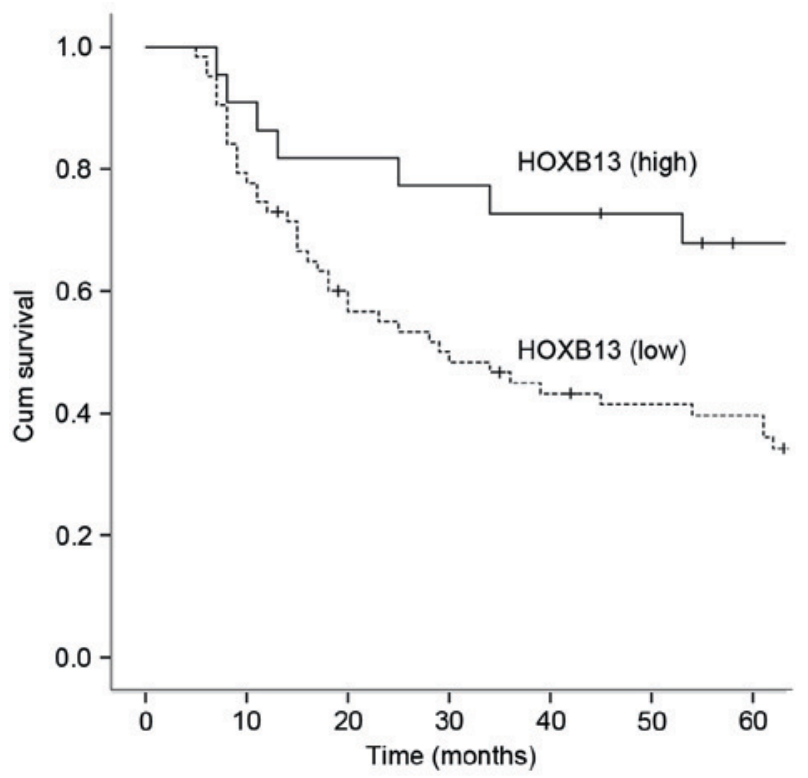

Figure 2. Univariate survival analysis of HOXB13 mRNA expression in gastric cancer. Kaplan-Meier curves for cumulative survival rate stratified by HOXB13 mRNA expression. A direct association between low expression of HOXB13 mRNA and a poor survival is presented. HOXB13, homeobox B13.

\section{A GES-1 MKN-45 BGC-823 MGC-803 AGC SGC-7901 IVD NB Marker $\overline{M U} \overline{M U} \overline{M U} \overline{M U} \overline{M U} \overline{M U} \bar{M} \overline{M U} \overline{M U}$

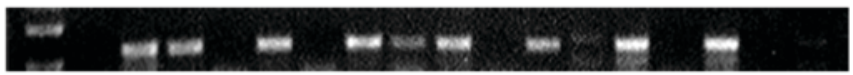

B

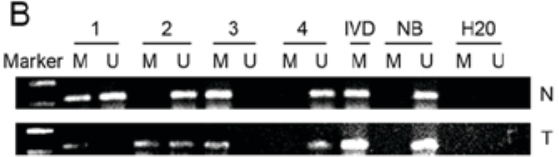

Figure 3. Methylation status of the HOXB13 gene in GC cell lines and GC tissues. (A) HOXB13 gene promoter was hypermethylated in BGC-823, AGS, MKN-45 and SGC-7901 cells, partially methylated in MGC-803 cells and unmethylated in GES1 cell. (B) HOXB13 gene promoter methylation status in GC tissues and corresponding nonmalignant gastric tissues. IVD was used as a positive control for methylation status, and NB samples were used as non-methylation positive control. GC, gastric cancer; HOXB13, homeobox B13; IVD, in vitro methylation DNA; NB, normal blood; M, methylated; U, unmethylated.

To verify the association between methylation of HOXB13 and HOXB13 expression further, 5-Aza-dC and TSA were used to treat the MKN-45 GC cell line, which had the lowest HOXB13
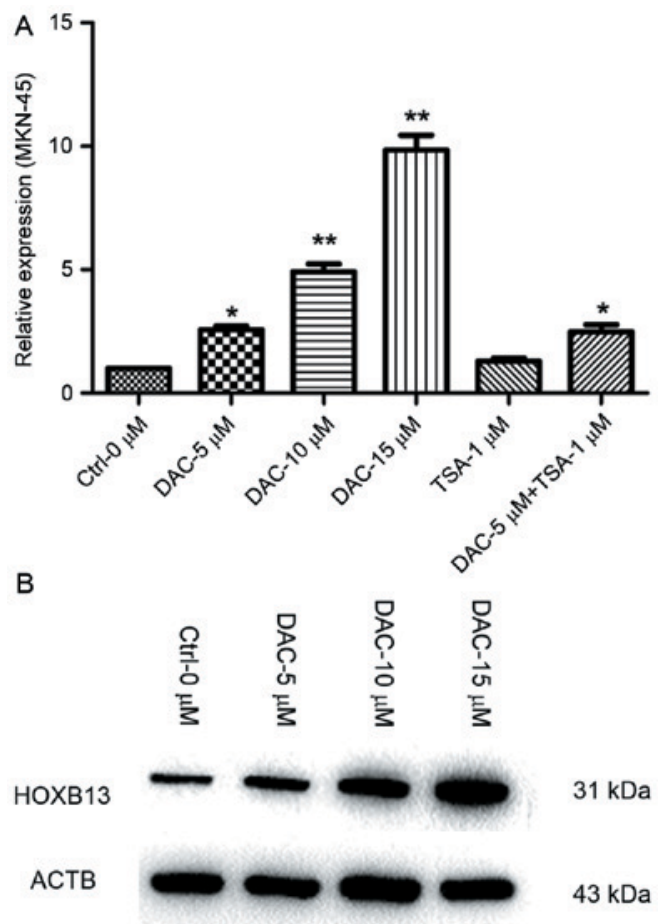

Figure 4. Effect of HOXB13 expression in the MKN-45 gastric cancer cell line following treatment with 5-Aza-dC. HOXB13 (A) mRNA and (B) protein expression in MKN45 cells following treatment with 5-Aza-dC $(5,10$ or $15 \mu \mathrm{M})$, TSA $(1.0 \mu \mathrm{M})$, or 5 -aza-dC $(5 \mu \mathrm{M})$ combined with TSA $(1 \mu \mathrm{M}) .{ }^{*} \mathrm{P}<0.05$ and ${ }^{* *} \mathrm{P}<0.01$ vs. Ctrl. HOXB13, homeobox B13; TSA, trichostatin A; Ctrl, control.

of all tested cell lines. The results demonstrated that 5-Aza-dC enhanced HOXB13 RNA and protein expression, but TSA had a weaker effect on HOXB13 expression. Additionally, the expression of HOXB13 was positively associated with 5-Aza-dC concentration. This result further demonstrated that expression of HOXB13 was regulated by DNA hypermethylation.

In conclusion, the present study indicated that HOXB13 was downregulated in GC, which was caused by DNA hypermethylation. HOXB13 mRNA expression was associated with tumor differentiation, invasion depth, lymph node metastases and TNM stage, and may be a potential prognostic factor for GC. The present study demonstrated that HOXB13 is a tumor suppressor gene in GC and has potential as a prognostic biomarker and as a target for pharmacological intervention. Further studies in vivo are necessary to determine the involvement of HOXB13 in GC progression. 


\section{Acknowledgements}

The authors would like to thank the researchers in the Laboratory of the Fourth Affiliated Hospital of China Medical University for their technical assistance.

\section{Funding}

This study was funded by the Natural Science Foundation of Liaoning (grant no. 201602817).

\section{Availability of data and materials}

The data and materials used analyzed during the current study are available from the corresponding author on reasonable request.

\section{Authors' contributions}

DQD was responsible for the design of the experiment and analysis and interpretation of data. BQS, CDZ, LW and JCL carried out the acquisition of data. BQS and CDZ were involved in drafting the manuscript and revising it critically for important intellectual content. All authors provided final approval of the version to be published.

\section{Ethics approval and consent to participate}

Research involving human subjects, human material or human data had be performed in accordance with the Declaration of Helsinki and had be approved by Ethics committee of the Fourth Affiliated Hospital of China Medical University. All participants consented to participate in this study.

\section{Consent for publication}

The patient, or parent, guardian or next of kin (in case of deceased patients) had provided written informed consent for the publication of any associated data and accompanying images.

\section{Competing interests}

The authors declare that they have no competing interests.

\section{References}

1. Shen L, Shan YS, Hu HM, Price TJ, Sirohi B, Yeh KH, Yang YH, Sano T, Yang HK, Zhang X, et al: Management of gastric cancer in Asia: Resource-stratified guidelines. Lancet Oncol 14: e535-e547, 2013.

2. Allemani C, Weir HK, Carreira H, Harewood R, Spika D, Wang XS, Bannon F, Ahn JV, Johnson CJ, Bonaventure A, et al: Global surveillance of cancer survival 1995-2009: Analysis of individual data for 25,676,887 patients from 279 population-based registries in 67 countries (CONCORD-2). Lancet 385: 977-1010, 2015.

3. Soubeyran P, Haglund K, Garcia S, Barth BU, Iovanna J and Dikic I: Homeobox gene cdx1 regulates ras, rho and pi3 kinase pathways leading to transformation and tumorigenesis of intestinal epithelial cells. Oncogene 20: 4180-4187, 2001.

4. Zhu JY, Sun QK, Wang W and Jia WD: High-level expression of HOXB13 is closely associated with tumor angiogenesis and poor prognosis of hepatocellular carcinoma. Int J Clin Exp Pathol 7: 2925-2933, 2014.
5. Ghoshal K, Motiwala T, Claus R, Yan P, Kutay H, Datta J, Majumder S, Bai S, Majumder A, Huang T, et al: HOXB13, a target of DNMT3B, is methylated at an upstream $\mathrm{CpG}$ island, and functions as a tumor suppressor in primary colorectal tumors. PLoS One 5: e10338, 2010.

6. Economides KD, Zeltser L and Capecchi MR: Hoxb13 mutations cause overgrowth of caudal spinal cord and tail vertebrae. Dev Biol 256: 317-330, 2003.

7. Jung C, Kim RS, Lee SJ, Wang C and Jeng MH: HOXB13 homeodomain protein suppresses the growth of prostate cancer cells by the negative regulation of T-cell factor 4. Cancer Res 64: 3046-3051, 2004.

8. Jung C, Kim RS, Zhang H, Lee SJ, Sheng H, Loehrer PJ, Gardner TA, Jeng MH and Kao C: HOXB13 is downregulated in colorectal cancer to confer TCF4-mediated transactivation. Br J Cancer 92: 2233-2239, 2005.

9. Decker B and Ostrander EA: Dysregulation of the homeobox transcription factor gene HOXB13: Role in prostate cancer. Pharmgenomics Pers Med 7: 193-201, 2014.

10. Chung N, Jee BK, Chae SW, Jeon YW, Lee KH and Rha HK: HOX gene analysis of endothelial cell differentiation in human bone marrow-derived mesenchymal stem cells. Mol Biol Rep 36: 227-235, 2009.

11. Zhang Q, Jin J and Tao Q: Aberrant methylation of tumor suppressor genes in renal cell carcinoma. Ai Zheng 26: 1276-1280, 2007 (In Chinese).

12. Muthusamy V, Duraisamy S, Bradbury CM, Hobbs C, Curley DP, Nelson B and Bosenberg M: Epigenetic silencing of novel tumor suppressors in malignant melanoma. Cancer Res 66: 11187-11193, 2006.

13. Tommasi S, Karm DL, Wu X, Yen Y and Pfeifer GP: Methylation of homeobox genes is a frequent and early epigenetic event in breast cancer. Breast Cancer Res 11: R14, 2009.

14. Okuda H, Toyota M, Ishida W, Furihata M, Tsuchiya M, Kamada M, Tokino T and Shuin T: Epigenetic inactivation of the candidate tumor suppressor gene HOXB13 in human renal cell carcinoma. Oncogene 25: 1733-1742, 2006.

15. Rauch T, Li H, Wu X and Pfeifer GP: MIRA-assisted microarray analysis, a new technology for the determination of DNA methylation patterns, identifies frequent methylation of homeodomain-containing genes in lung cancer cells. Cancer Res 66: 7939-7947, 2006

16. Ewing CM, Ray AM, Lange EM, Zuhlke KA, Robbins CM, Tembe WD, Wiley KE, Isaacs SD, Johnq D, Wang Y, et al: Germline mutations in HOXB13 and prostate-cancer risk. N Engl J Med 366: 141-149, 2012.

17. Ang MK, Ooi AS, Thike AA, Tan P, Zhang Z, Dykema K, Furge K, Teh BT and Tan PH: Molecular classification of breast phyllodes tumors: Validation of the histologic grading scheme and insights into malignant progression. Breast Cancer Res Treat 129: 319-329, 2012.

18. Miao J, Wang Z, Provencher H, Muir B, Dahiya S, Carney E, Leong CO, Sgroi DC and Orsulic S: HOXB13 promotes ovarian cancer progression. Proc Natl Acad Sci USA 104: 17093-17098, 2007.

19. Yuan H, Kajiyama H, Ito S, Chen D, Shibata K, Hamaguchi M, Kikkawa $F$ and Senga T: HOXB13 and ALX4 induce SLUG expression for the promotion of EMT and cell invasion in ovarian cancer cells. Oncotarget 6: 13359-13370, 2015.

20. Lopez R, Garrido E, Piña P, Hidalgo A, Lazos M, Ochoa R and Salcedo M: HOXB homeobox gene expression in cervical carcinoma. Int J Gynecol Cancer 16: 329-335, 2006.

21. De Souza Setubal Destro MF, Bitu CC, Zecchin KG, Graner E, Lopes MA, Kowalski LP and Coletta RD: Overexpression of HOXB7 homeobox gene in oral cancer induces cellular proliferation and is associated with poor prognosis. Int J Oncol 8: 141-149, 2010.

22. Maia S, Cardoso M, Pinto P, Pinheiro M, Santos C, Peixoto A, Bento MJ, Oliveira J, Henrique R, Jeronimo $\mathrm{C}$ and Teixeira MR: Identification of two novel HOXB13 germline mutations in portuguese prostate cancer patients. PLoS One 10: e0132728, 2015.

23. Beebe-Dimmer J, Hathcock M, Yee C, Okoth LA, Ewing CM, Isaacs WB, Cooney KA and Thibodeau SN: The HOXB13 G84E mutation is associated with an increased risk for prostate cancer and other malignancies. Cancer Epidemiol Biomarkers Prev 24: 1366-1372, 2015.

24. Brierley JD, Gospodarowicz MK, Wittekind C (eds): TNM classification of malignant tumours. Wiley-Black well 80: 1803-1804, 2010. 
25. Wang Z, Dahiya S, Provencher H, Muir B, Carney E, Coser K, Shioda T, Ma XJ and Sgroi DC: The prognostic biomarkers HOXB13, IL17BR, and CHDH are regulated by estrogen in breast cancer. Clin Cancer Res 13: 6327-6334, 2007.

26. Livak KJ and Schmittgen TD: Analysis of relative gene expression data using real-time quantitative PCR and the 2(-Delta Delta C(T)) method. Methods 25: 402-408, 2001.

27. Wang F, Yang Y, Fu Z, Xu N, Chen F, Yin H, Lu X, Shen R and Lu C: Differential DNA methylation status between breast carcinomatous and normal tissues. Biomed Pharmacother 68 699-707, 2014.

28. Japanese Gastric Cancer Association: Japanese classification of gastric carcinoma-2nd English edition. Gastric Cancer 1: 10-24, 1998.

29. Gopalakrishnan S, Van Emburgh BO and Robertson KD: DNA methylation in development and human disease. Mutat Res 647: 30-38, 2008

30. Kanwal R and Gupta S: Epigenetics and cancer. J Appl Physiol (1985) 109: 598-605, 2010.

31. Chang X, Zhang S, Ma J, Li Z, Zhi Y, Chen J, Lu Y and Dai D: Association of NDRG1 gene promoter methylation with reduced NDRG1 expression in gastric cancer cells and tissue specimens. Cell Biochem Biophys 66: 93-101, 2013.
32. Xu X, Chang X, Li Z, Wang J, Deng P, Zhu X, Liu J, Zhang C, Chen S and Dai D: Aberrant SOX11, promoter methylation is associated with poor prognosis in gastric cancer. Cell Oncol (Dordr) 38: 183-194, 2015.

33. Zhang J, Li Y, Liu J, Zhang C and Dai D: Epigenetic regulation of microrna-335 and its clinical significance in gastric cancer. J Modern Oncol, 2016.

34. Zeltser L, Desplan C and Heintz N: Hoxb-13: A new Hox gene in a distant region of the HOXB cluster maintains colinearity. Development 122: 2475-2484, 1996.

35. Marra L, Cantile M, Scognamiglio G, Perdonà S, La Mantia E, Cerrone M, Giqantino V, Cillo C, Caraqlia M, Piqnata S, et al: Deregulation of HOX B13 expression in urinary bladder cancer progression. Curr Med Chem 20: 833-839, 2013

36. Varinot J, Cussenot O, Roupret M, Conort P, Bitker MO, Chartier-kastler E, Cheng L and Compérat E: HOXB13 is a sensitive and specific marker of prostate cells, useful in distinguishing between carcinomas of prostatic and urothelial origin. Virchows Arch 463: 803-809, 2013 